\title{
Study on Dynamics of Polygonal Wear of Automotive Tire Caused by Self-Excited Vibration
}

\author{
Shuguang Zuo, ${ }^{1,2}$ Xianglei Duan, ${ }^{1,2}$ and Yong $\mathrm{Li}^{1,2}$ \\ ${ }^{1}$ Clean Energy Automotive Engineering Center, Tongji University, Shanghai 201804, China \\ ${ }^{2}$ School of Automobile Studies, Tongji University, Shanghai 201804, China \\ Correspondence should be addressed to Shuguang Zuo; sgzuo@tongji.edu.cn
}

Received 15 April 2014; Accepted 21 July 2014; Published 12 August 2014

Academic Editor: Hongyong Zhao

Copyright (c) 2014 Shuguang Zuo et al. This is an open access article distributed under the Creative Commons Attribution License, which permits unrestricted use, distribution, and reproduction in any medium, provided the original work is properly cited.

\begin{abstract}
Considering the underlying reason of tire polygonal wear, a unified mechanical tire model is developed to analyze the different vibration properties between the driving wheel and follower wheel. And the LuGre dynamic friction model is applied to determine the frictional forces between the wheel with a slip angel and the road. Through the stability analysis with Lyapunov theory, it is found that tread self-excited vibration is periodic oscillation caused by Hopf bifurcation. The analysis of the lateral vibration of driving wheel shows that the tread vibration system loses its stability and self-excited vibration occurs when the wheel is rolling at a high speed, is over-loaded, is having a large toe-in angle, or is under a low tire pressure. On this basis, the dynamic behaviors of the driving and follower wheels are distinguished with different slip rates by the numerical simulation. Compared with the dynamic behaviors of the follower wheel under the same condition, the self-excited vibration occurs on the driving wheel with more limited parameter scope, lower oscillation energy, and lower occurrence, which explains why the polygonal wear is less likely to occur on the driving wheel.
\end{abstract}

\section{Introduction}

With the development of modern highway, it makes vehicle travel more convenient and faster, while the polygonal wear, which occurs more frequently on the automotive tire, has become a serious problem. As shown in Figure 1 [1], the inhomogeneous wear is circumferentially upon the tire in the form of an 18-gon. And the wear shape is slightly slanted from the tire axial direction. The tire will be easily scrapped because of the polygonal wear, which may subsequently result in a series of accidents.

Up to now, there are few reports about the research on the polygonal wear. The Sueoka et al. $[1,2]$ research group from Japan contributed a lot to this subject. The group drew a conclusion that tire polygonal wear was merely caused by the vertical self-excited vibration, and they also put forward an empirical formula to figure out the number of edges of the polygonal wear. Sueoka et al. [1] proposed that how much the tire was instantaneously subject to wear depends on the lateral force. However, they merely undertook the examination on tire's vertical vibration characteristics and failed to delve into how the lateral vibration was linked to the polygonal wear, which could not be resorted to explain the tire polygonal wear. The lateral vibration is likely to happen when the follower wheel runs at a steady speed in the lateral direction. Regarding this issue, Zuo Shuguang and his group [3-5] in Tongji University had analyzed the tire lateral vibration in terms of the tire wear. According to their study, tire polygonal wear is typically a phenomenon of nonlinear self-excited vibration which is related to tread lateral self-excited vibration. Nevertheless, tread lateral selfexcited vibration is not sufficiently the condition causing the wear. The polygonal wear also requires the tire to run a sufficient long distance at a specific speed which makes the frequency of the lateral self-excited vibration divisible by the rolling frequency of the wheel. But the analysis of Zuo Shuguang focused on the follower wheel alone and cannot explain the differences between the follower wheel and driving wheel about the polygonal wear.

Since the tread lateral self-excited vibration is a major reason for the tire polygonal wear and the follower wheel 

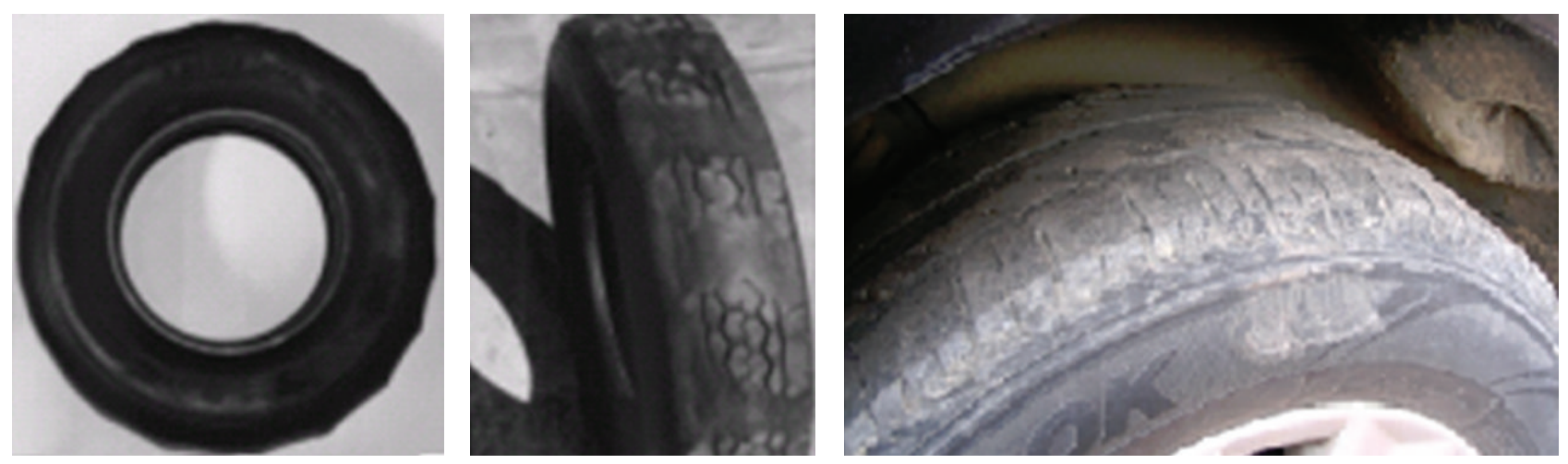

Figure 1: Polygonal wear on the tire.

model is not applicable to explain the differences between the follower wheel and driving wheel, a unified mechanical tire model is built up based on the research results of Zuo Shuguang to discriminate the dynamic characteristics of the driving wheel and follower wheel. Then the conditions under which the tread lateral self-excited vibration is caused will be determined. Consequently the phenomenon that the follower wheel is more likely to suffer polygonal wear than the driving one will be explained in terms of the comparison with respect to the range of the conditions in which the self-excited vibration is caused.

The essay is constructed as follows: in Section 2, the brush model is introduced to analyze the tire-road contact characteristics of the follower wheel; in Section 3, the tread dynamic lateral vibration model is established with the LuGre friction Model. The maximum of static frictional force and the sliding frictional force will be obtained from the equations of the first part; Section 4 will discuss the stability of lateral vibration model, and a comparison will be given with respect to the range of the conditions of the follower and driving wheels.

\section{Tire-Road Contact Characteristics of Driving Wheel}

Before turning to driving wheel's tread vibration characteristics, it is rewarding to analyze its tire-road contact properties. This part purports to fulfill this task with reference to the research in On Modern Tire Technology (2001).

Figure 2 [6] shows the deformation of the road contact part of the tire when the driving wheel is rolling with a certain slip angle $\alpha$. The point on the road moves inthe line " $a$ ' $b$ ", while the point on the bottom of tread moves in the line " $a$ ' $c$ ". When a point on the tread contacts the ground at the point " $a$ ", it will move to the point " $b$ " and then slide to the point " $d$ ". The line " $a$ ' $c$ " stands for the sticking area, while the line " $c d$ " stands for the sliding area. The cutoff point " $c$ " is the starting point of the sliding area which has a corresponding coordinate $X_{c}$ on the $X$-axis.

According to the research in On Modern Tire Technology (2001), the longitudinal stress $f_{x}$ and lateral stress $f_{y}$ of

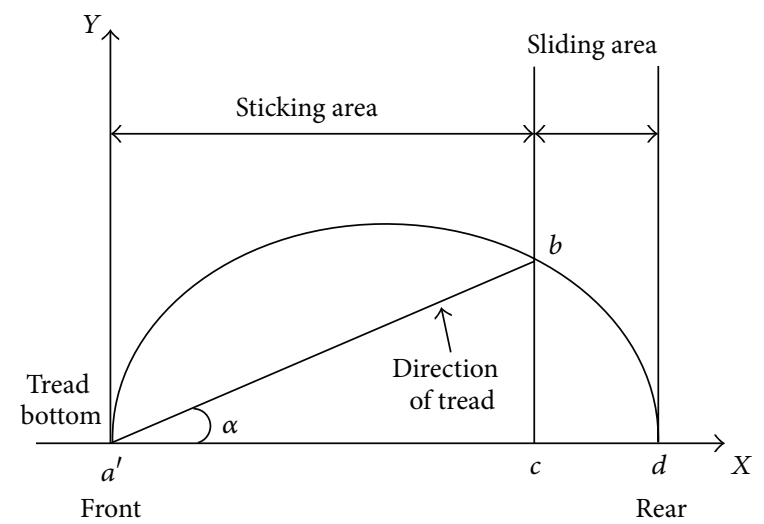

Figure 2: Deformation condition of the grounded part of the tire.

the tread rubber in the sticking area in driving conditions are defined as

$$
\begin{gathered}
f_{x}=C S X \\
f_{y}=C X(1+S) \tan \alpha .
\end{gathered}
$$

In the equations above, the symbol $C$ stands for the tangential elastic constant of the rubber; $X$ is the coordinate of contact point; $S$ stands for the sliding ratio; and $\alpha$ represents the slip angle. The longitudinal force $F_{X f}$ and the lateral force $F_{Y f}$ between the ground and the tread are defined as

$$
\begin{gathered}
F_{x f}=\int_{0}^{X_{c}} \operatorname{CbS} X d X=\frac{C b S X_{c}^{2}}{2} \\
F_{y f}=\int_{0}^{X_{c}} C b X(1+S) \tan \alpha d X=\frac{C b(1+S) X_{c}^{2}}{2} \tan \alpha .
\end{gathered}
$$

Supposing that the shape of the grounded tread is a rectangle and its length is represented by the symbol $a$, and the width is represented by $b$, the pressure distribution of the tire-road contact around the circle can be written as

$$
p=\frac{n+1}{n} \frac{2^{n} F_{Z}}{a^{n+1} b}\left[\left(\frac{a}{2}\right)^{n}-\left(X-\frac{a}{2}\right)^{n}\right] .
$$




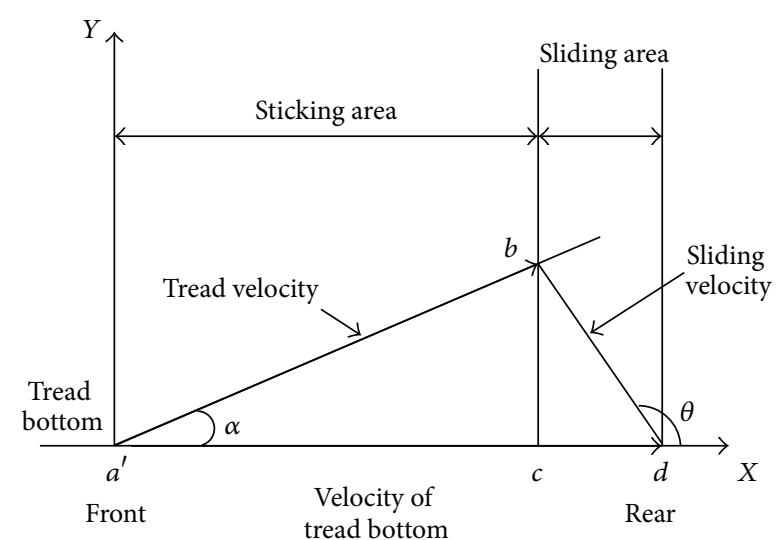

FIGURE 3: Velocity relationship between different parts of tire in driving condition.

In the equation above, the symbol $p$ stands for the function of the pressure distribution, $F_{Z}$ is the vertical load on the tire, and $n$ is the distribution coefficient, normally taking $n=[2, \ldots, 6]$ according to Zhuang [6].

As shown in Figure 2, the force equilibrium equation of the point " $c$ " can be written as

$$
f_{x}^{2}+f_{y}^{2}=\left(p \mu_{m}\right)^{2},
$$

where the symbol $\mu_{m}$ represents the coefficient of the maximum static frictional force and $f_{x}$ and $f_{y}$ are the longitudinal and lateral stress of point $c$, respectively.

With $n=2$ and (1), (3), and (4), $X_{c}$ can be represented as

$$
\begin{gathered}
X_{c}=a(1-q) \\
q=\frac{C b a^{2} \sqrt{(1+S)^{2} \tan ^{2} \alpha+S^{2}}}{6 \mu_{m} F_{Z}},
\end{gathered}
$$

where $q$ is the ratio between the length of the sliding area and contact area. By putting (5) into (2), the frictional forces in the sticking area become

$$
\begin{gathered}
F_{x f}=\frac{C b S a^{2}(1-q)^{2}}{2} \\
F_{y f}=\frac{C b(1+S) a^{2}(1-q)^{2}}{2} \tan \alpha .
\end{gathered}
$$

In the tire-road contact area, the relative sliding velocity between the tread and the road, the tread velocity $V$ and the velocity $V_{b}$ of tread bottom have the relationship as shown in Figure 3 [6], where $\theta$ is the angel between the direction of the frictional force and the velocity of the tread bottom.

From Figure 3 the following equation can be obtained:

$$
\frac{V \sin \alpha}{-\left(V \cos \alpha-V_{b}\right)}=\tan (\pi-\theta) \text {. }
$$

The slip ratio is defined as

$$
S=\frac{V \cos \alpha-V_{b}}{V_{b}}
$$

With (8), (7) is finally presented as

$$
\tan \theta=\frac{S+1}{S} \tan \alpha .
$$

In the sliding area, the frictional force disassembled in the $X$ and $Y$ direction become

$$
\begin{aligned}
F_{X h} & =\int_{X_{c}}^{a} p \mu b \cos (\pi-\theta) d X=-\int_{X_{c}}^{a} p \mu b \cos \theta d X \\
& =-\int_{X_{c}}^{a} \mu \cos \theta \frac{6 F_{z} X}{a^{2}}\left(1-\frac{X}{a}\right) d X \\
F_{Y h} & =\int_{X_{c}}^{a} p \mu b \sin (\pi-\theta) d X=\int_{X_{c}}^{a} p \mu b \sin \theta d X \\
& =\int_{X_{c}}^{a} \mu \sin \theta \frac{6 F_{z} X}{a^{2}}\left(1-\frac{X}{a}\right) d X .
\end{aligned}
$$

By taking the integral of the frictional force in the sliding area and combining with (6), the longitudinal and lateral frictional forces in the whole tire-road contact area become

$$
\begin{aligned}
F_{X}= & F_{X f}+F_{X h}=\frac{C b S a^{2}(1-q)^{2}}{2} \\
& +\mu F_{Z} q^{2}(3-2 q) \frac{S}{\sqrt{(S+1)^{2} \tan ^{2} \alpha+S^{2}}} \\
F_{Y}= & F_{Y f}+F_{Y h}=\frac{C b(1+S) a^{2}(1-q)^{2}}{2} \tan \alpha \\
& +\mu F_{Z} q^{2}(3-2 q) \frac{(S+1) \tan \alpha}{\sqrt{(S+1)^{2} \tan ^{2} \alpha+S^{2}}} .
\end{aligned}
$$

The contact footprint between tread and ground is affected by such factors as tire structure, the wheel alignment parameters, the pressure, and the load on the tire. According to tire deformation characteristics in light of Zhuang [6] and Li et al. [5], the length and width of the tire-road contact area are calculated with

$$
\begin{gathered}
a=4 r_{B}\left(\frac{\delta}{2 r_{B}}\right)^{\xi} \\
b=b_{0}\left(1-e^{-\psi \delta}\right) .
\end{gathered}
$$

In the equations above, the symbol $b_{0}$ stands for the width of the tire crown; $r_{B}$ stands for tire radius; $\xi$ and $\psi$ stand for the empirical coefficients related to tire structure; $\delta$ represents the maximum subsidence related to many factors, for example, the tire structure, the tire pressure, the load on the tire, and so forth. According to Yu [7], $\delta$ can be given as follows:

$$
\delta=\frac{\alpha_{1} F_{z}}{2 p}+\sqrt{\left(\frac{\alpha_{1} F_{z}}{2 p}\right)^{2}+\alpha_{2} F_{z}}
$$

In the equation above, the constant $\alpha_{1}$ is defined as $\alpha_{1}=1 /\left(2 \pi \sqrt{r_{B} r_{w}}\right)$, where $r_{w}$ is the tread lateral curvature 


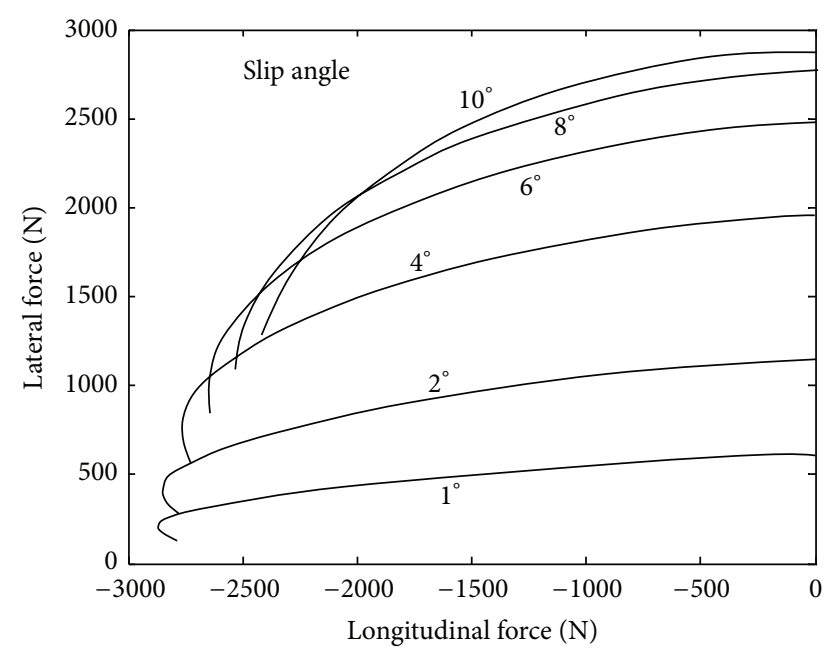

FIGURE 4: Relationship between longitudinal and lateral forces in different conditions of slip angels.

radius. For the vehicle tire, the constant $\alpha_{2}$ is defined as 3.7 $\times 10^{-8} \mathrm{~m}^{2} / \mathrm{N}$.

The length and width of the tire-road contact area can be obtained from (13). Putting the results into (11) and (12), the relationship between the longitudinal and lateral forces at different slip angles is identified, as shown in Figure 4.

Figure 4 shows that the envelope of a series of curves is getting closer to an ellipse, called the adhesion ellipse. Under a certain slip angle, tread lateral force reduces gradually with the longitudinal driving force increasing. When the driving force is going up to a larger degree, the lateral force will decrease significantly. Because at this moment the driving force is approaching the adhesion limit under which condition the driving force has exhausted most of the adhesion force and little adhesion force is available for lateral force.

The friction ellipse caused by the adhesion limit is adopted to explain the relation between the two forces. With the identified parameters, the sliding friction coefficient and the maximum static friction coefficient from the references, the steady-state forces of brush model, show good agreement with those of the Pacejka tire model. Then the steady-state forces including the sliding frictional force and the maximum static frictional force calculated by the brush model are used in the LuGre dynamic model to get the dynamic frictional force in the next section.

When a vehicle is running in straight-line motion, it must overcome the rolling resistance and air resistance. The driving force can be obtained by the longitudinal component of the resultant force of the rolling resistance and air resistance. According to the force equilibrium equation, the driving force, the slip ratio, and the lateral force can be, respectively, obtained with the slip angle.

\section{Tread Vibration Model}

To analyze tire lateral vibration, the ground contact mass is taken as the research object. The contact part of the tire

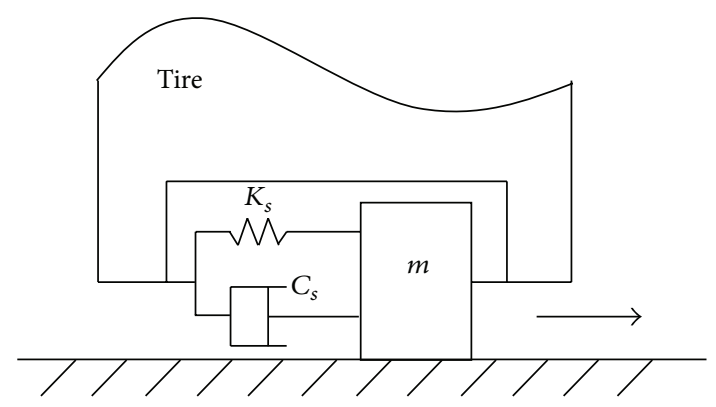

FIGURE 5: The tread vibration model.

is treated as the concentrated mass to simplify the analytical calculation. Under this assumption, the tire model is simplified as the tread vibration model. The connection between the mass and the whole tire can be shown in Figure $5 . K_{S}$ is the lateral rigidity, $C_{S}$ is the lateral damping, and $m$ is the mass of the tread.

It should be noted that the tire is in straight-line motion, which is in accordance with the conditions that lead to the tire polygonal wear. The wheel alignment parameters can be considered as the initial conditions of the tire dynamics model. The toe-in angle and the side slip angle are not distinguished in this paper. Both the toe-in angle and the side slip angle are considered as the included angle between the tire plane and the vehicle velocity. The other alignment parameters are not set as the design parameter except the toein angle. So the influences of the other alignment parameters on the tire wear can be explained from the perspective of the toe-in angle.

The letter $\alpha$ represents the toe-in angle in the rest of this paper. The forward velocity of tire is divided into the longitudinal and lateral directions so as the tread has the velocity of the two directions meanwhile. The power of the tread lateral vibration comes from the continuous frictional force between the tread and the ground, which means that the relative velocity is the excitation source as a result.

According to the Newton-Euler dynamics equations, the equilibrium equation of the tread vibration model becomes

$$
m \frac{d^{2} y}{d t^{2}}+C_{s} \frac{d y}{d t}+K_{s} y+F_{Y}=0 .
$$

$F_{Y}$ is the lateral force in (15). $K_{S}$ can be calculated from the following equation by $\mathrm{Li}$ et al. [5] as shown in

$$
K_{s}=G b \beta\left(1-\frac{48}{\pi^{2}\left(6+\pi^{2} \beta^{2}\right)}\right) .
$$

In the equation above, $G$ is the elastic shear modulus of the tread rubber; $\beta$ is the length-width ratio of the concentrated tread part.

The tire-road contact characteristics of the driving wheel have been analyzed to obtain the frictional force in the tireroad contact area. For the fast rolling wheel, the tire-road contact area is constantly varied from the sticking area to the sliding area. Ding [8] presents that the self-excited vibration in the contact area is mainly caused by the negative damping 
effect of the tread-road kinetic friction in the sliding area. To analyze the characteristics of tread lateral self-excited vibration of both the driving and follower wheel clearly, the sliding area is assumed to cover all proportion of the contact area. Dividing the second item of (12) by $q, F_{Y}$ is obtained as follows:

$$
\begin{aligned}
F_{Y} & =\mu F_{Z} q^{2}(3-2 q) \frac{(S+1) \tan \alpha}{q \sqrt{(S+1)^{2} \tan ^{2} \alpha+S^{2}}} \\
& =\mu F_{Z} q(3-2 q) \frac{(S+1) \tan \alpha}{\sqrt{(S+1)^{2} \tan ^{2} \alpha+S^{2}}} .
\end{aligned}
$$

In the equation above, the coefficient of kinetic friction $\mu$ varies with the relative velocity between the road and tread, which affects the tread lateral vibration form. From (17), the steady frictional forces including the maximum static frictional force and the steady sliding frictional force can be obtained.

In the tread-road vibration model, the description of the characteristic of the dynamic friction has invariably become an important and difficult part in the construction of the tire mechanics model, which pertains directly to the precision of the model. In this essay, the LuGre friction model proposed by Canudas de Wit [9] will be adopted, as shown in

$$
\begin{gathered}
F=\sigma_{0} z+\sigma_{1} \frac{d z}{d t}+\sigma_{2} v_{r} \\
\frac{d z}{d t}=v_{r}-\frac{\sigma_{0}\left|v_{r}\right|}{G\left(v_{r}\right)} \cdot z \\
G\left(v_{r}\right)=F_{s}+\left(F_{m}-F_{s}\right) e^{-\left|v_{r} / v_{s}\right|^{\phi}} .
\end{gathered}
$$

The following notations are used: $\sigma_{0}$ is the brush stiffness coefficient, which is equal to the lateral rigidity of the tread, namely, $\sigma_{0}=K_{s} ; \sigma_{1}$ is the brush damping coefficient; $\sigma_{2}$ is the relative viscous damping coefficient; $z$ is the average elastic deformation of brush; $v_{r}$ is the relative velocity of the contacted surface; $v_{s}$ is the Stribeck speed in the characteristics of the static friction; $\phi$ is the Stribeck index (normally taken as $\alpha \in[0.5,2]) ; F_{s}$ is the sliding frictional force; $F_{m}$ is the maximum static frictional force. $F_{m}$ and $F_{s}$ in (18) can be, respectively, expressed as follows:

$$
\begin{aligned}
& F_{m}=\mu_{m} F_{Z} q(3-2 q) \frac{(S+1) \tan \alpha}{\sqrt{(S+1)^{2} \tan ^{2} \alpha+S^{2}}} \\
& F_{s}=\mu_{s} F_{Z} q(3-2 q) \frac{(S+1) \tan \alpha}{\sqrt{(S+1)^{2} \tan ^{2} \alpha+S^{2}}},
\end{aligned}
$$

where $\mu_{m}$ and $\mu_{s}$ are the maximum static friction coefficient and sliding friction coefficient, respectively.
Ignoring the relative viscosity between the tire and road, namely, $\sigma_{2}=0$, the differential equation defining the tread lateral vibration of the driving wheel becomes

$$
\begin{aligned}
\frac{d z}{d t}= & \frac{d y}{d t}-V \sin \alpha-\frac{|(d y / d t)-V \sin \alpha|}{F_{s}+\left(F_{m}-F_{s}\right) e^{-\left|((d y / d t)-V \sin \alpha) / V_{s}\right|}} \\
& \cdot K_{s} z \\
& m \frac{d^{2} y}{d t^{2}}+C_{s} \frac{d y}{d t}+K_{s} y+K_{s} z+C_{s} \frac{d z}{d t}=0 .
\end{aligned}
$$

According to the method of Li et al. [5], (20) can be finally presented as a first order form as

$$
\begin{gathered}
\frac{d x_{1}}{d t}=x_{3}-V \sin \alpha-\frac{\left|x_{3}-V \sin \alpha\right|}{F_{s}+\left(F_{m}-F_{s}\right) e^{-\left|\left(x_{3}-V \sin \alpha\right) / V_{s}\right|}} \cdot K_{s} x_{1} \\
\frac{d x_{2}}{d t}=x_{3} \\
\frac{d x_{3}}{d t}=-\frac{1}{m}\left(C_{s} x_{3}+K_{s} x_{2}+K_{s} x_{1}+C_{s} \frac{d x_{1}}{d t}\right) .
\end{gathered}
$$

In (21), $x_{1}=z, x_{2}=y$, and $x_{3}=d y / d t$. Equation (21) describes the evolutionary process of the driving wheel's tread lateral movement. The solution corresponds to a certain situation in the movement system; for example, the balance point corresponds to the stability of the lateral movement, which means the lateral displacement and speed of the tread remain unchanged, while the periodic solution indicates that the lateral displacement and speed change periodically in a certain frequency, meaning that the system is in a state of selfexcited vibration.

Meanwhile, taking the follower wheel as a special case of the driving wheel, this equation can be applied to the follower wheel as long as the slip ratio is defined as $S=0$ in (19).

\section{The Bifurcation of the Tread Lateral Vibration Model}

4.1. The Stability of the Vibration System. In the engineering practice, it is often required to judge whether a movement is stable or not, that is, whether the law of perturbing is still very similar to that of not being perturbed when a slight disturbance is caused on the state variables. The Lyapunov's stability theory [10] enables us to solve differential equation and the properties of the solutions can be used to judge the stability. The nonlinear system, when it is within a certain scope of the working point, then, can be approximately described by the linear differential equation. This is also similar to the Floquet theory adopted by van de Vorst [11] in stability analysis. When the real parts of eigenvalues for the characteristic equation are all with negative values, the system is in a stability state. While with a zero value, the stability of the system may be disturbed by the Hopf bifurcation, which will lead to the periodic oscillation and selfexcited vibration. The tire self-excited vibration, therefore, is 
the periodic oscillation caused by the Hopf bifurcation. Then the tread wear is the superposition of the even and disturbing wear, which may cause the tire polygonal wear.

Since the zero solution to the equation without disturbance is equivalent to zero solution to the equation with disturbance, the stability above can be transformed into the stability of the zero solution.

From $d x_{1} / d t=0, d x_{2} / d t=0$, and $d x_{3} / d t=0$, the balance point of (21) can be expressed as

$$
\begin{gathered}
x_{10}=-\frac{F_{S}+\left(F_{m}-F_{S}\right) e^{-\left|V \sin \alpha / V_{S}\right|^{\phi}}}{K_{S}} \\
x_{20}=\frac{F_{S}+\left(F_{m}-F_{S}\right) e^{-\left|V \sin \alpha / V_{S}\right|^{\phi}}}{K_{S}} \\
x_{30}=0 .
\end{gathered}
$$

To analyze the stability of the solution, the $x_{i}(t)$ can be expressed as a solution close to the real one which can be written as

$$
x_{i}(t)=x_{i 0}(t)+\zeta_{i}(t)
$$

where $\zeta_{i}(t)$ is the deviation of the state quantity from the balance point.

Equation (21) can be rewritten as

$$
\frac{d x_{i}}{d t}=f_{i}\left(x_{j}\right) \quad(i, j=1,2,3) .
$$

Substituting (23), the Taylor series can be expanded as

$$
\begin{aligned}
\frac{d x_{i 0}(t)}{d t}+\frac{d \zeta_{i}(t)}{d t} & =f_{i}\left(x_{j}\right)=f_{i}\left(x_{j 0}+\zeta_{j}\right) \\
& =f_{i}\left(x_{j 0}\right)+\sum_{j}\left(\frac{\partial f_{i}}{\partial x_{j}}\right)_{0} \zeta_{j}+0\left(\zeta_{j}^{2}\right) .
\end{aligned}
$$

In the equation, $0\left(\zeta_{j}^{2}\right)$ represents the infinitive minor term of $\zeta_{j}$ in terms of quadratic and higher order, while the subscript 0 stands for the balance point.

If the high-order term is neglected, (25) becomes

$$
\frac{d \zeta_{j}(t)}{d t}=\sum_{j}\left(\frac{\partial f_{i}}{\partial x_{j}}\right)_{0} \zeta_{j}=A\left(x_{j}\right) \zeta_{j},
$$

where $A\left(x_{j}\right)$ is the Jacobi matrix when the function $f_{i}\left(x_{j}\right)$ is at the balance point $y_{i 0}(t)$.

For the Hopf bifurcation of a nonlinear system, it can be judged whether there are eigenvalues that cross the virtual axis when the parameters change by calculating all the eigenvalues of Jacobi matrix $A\left(x_{j}\right)$. In other words, the bifurcation point is the one whose real part of the eigenvalue is zero.

From the data of our previous work and the references $[5,9,12,13]$, the structure parameters of the tire, system parameters, and parameters of the LuGre model are listed as follows.

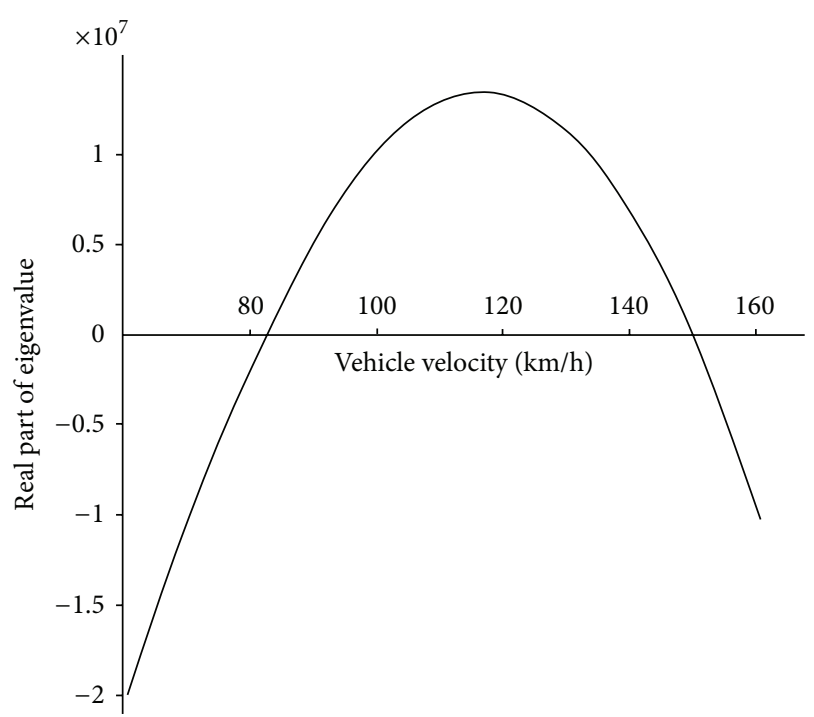

FIGURE 6: Variation trend of the real part of eigenvalues corresponding to vehicle velocity.

Figure 6 shows the variation trend identifying that the real part of the eigenvalues of the Jacobi matrix changes with the vehicle velocity, and the real part of the eigenvalues is mainly concerned with the lateral vibration system of the follower wheel. When the velocity is relatively low, the real parts of the eigenvalues are negative, meaning that the balance point of the system is stable and there is no lateral selfexcited vibration in the tread part. When the velocity reaches around $82 \mathrm{~km} / \mathrm{h}$, the real parts of the eigenvalues are zero. The Jacobi matrix of the follower wheel system has a pair of pure imaginary eigenvalues; then the vibration system may be unstable and the Hopf bifurcation will be caused at the balance point. When the velocity reaches more than $82 \mathrm{~km} / \mathrm{h}$, the real parts of the eigenvalues are greater than zero and the periodic vibration will occur, which indicates that the lateral self-excited vibration appears. With vehicle velocity increasing, the real parts of the Jacobi matrix's eigenvalues will turn from positive to negative. When the velocity is higher than $150 \mathrm{~km} / \mathrm{h}$, the vibration system will be stable again.

It can be concluded that the stability of the system varies with different parameters and the self-excited vibration only is caused with certain parameters. In the following part, the range of parameters of the tread self-exited vibration will be achieved through the numerical simulation.

\subsection{Simulation of the Tread Lateral Vibration}

4.2.1. The Tread Lateral Vibration of the Follower Wheel. The dynamic behaviors of both the follower wheel and driving wheel will be analyzed by taking the vehicle velocity, toe-in angle, vertical load, and tire pressure as the bifurcate parameters. In the analysis of the tire-road contact characteristics, the follower wheel is regarded as a special situation of the driving 
TABLE 1: The system parameters.

\begin{tabular}{lccc}
\hline System parameter & Symbol & Value & Unit \\
\hline Coefficient of air resistance & $C_{D}$ & 0.315 & $/$ \\
Windward area & $A$ & 2.0 & $\mathrm{~m}^{2}$ \\
Tread mass density & $\rho$ & 1250 & $\mathrm{~kg} / \mathrm{m}^{3}$ \\
Vertical load & $F_{Z}$ & 4000 & $\mathrm{~N}$ \\
Toe-in angle & $\alpha$ & 0.3 & $\mathrm{deg}$ \\
Structure constant of tire & $\zeta$ & 0.67 & $/$ \\
Structure constant of tire & $\psi$ & 115 & $/$ \\
Crown width of tire & $b_{0}$ & 0.166 & $\mathrm{~m}$ \\
The lateral curvature radius of tire & $r_{w}$ & 0.155 & $\mathrm{~m}$ \\
The radius of tire & $r_{B}$ & 0.317 & $\mathrm{~m}$ \\
Pressure of tire & $P$ & 280 & $\mathrm{kPa}$ \\
Tread lateral damping & $C_{s}$ & 10 & $\mathrm{~N} \cdot \mathrm{s} / \mathrm{m}$ \\
The height of tread & $h$ & 0.015 & $\mathrm{~m}$ \\
\hline
\end{tabular}

TABLE 2: LuGre model parameters.

\begin{tabular}{lccc}
\hline System parameter & Symbol & Value & Unit \\
\hline Coefficient of maximum static friction & $\mu_{m}$ & 0.76 & $/$ \\
Coefficient of sliding friction & $\mu_{S}$ & 0.63 & $/$ \\
Stribeck speed & $v_{s}$ & 0.162 & $\mathrm{~m} / \mathrm{s}$ \\
Stribeck index & $\phi$ & 0.9 & $/$ \\
Brush damping coefficient & $\sigma_{1}$ & 10 & $\mathrm{~N} \cdot \mathrm{s} / \mathrm{m}$ \\
Relative to the viscous damping coefficient & $\sigma_{2}$ & 0 & $\mathrm{~N} \cdot \mathrm{s} / \mathrm{m}$ \\
\hline
\end{tabular}

wheel; that is, the slip ratio represented by the symbol $S$ is 0 in (17) and (18).

(1) Impact of the Vehicle Velocity on the Lateral Vibration of the Follower Wheel. By setting the parameters as shown in Tables 1 and 2 , the bifurcation with the variation of vehicle velocity is shown in Figure 7.

Figure 8 shows that the system is in stability when the vehicle velocity is low (at $78 \mathrm{~km} / \mathrm{h}$ ), which indicates that there is no self-excited vibration on the tread. However, the system loses its stability when the vehicle velocity is up to $81.7 \mathrm{~km} / \mathrm{h}$, leading to the periodic oscillation caused by Hopf bifurcation as shown in Figure 9; that is, the self-excited vibration occurs on the tread. By analyzing the self-power spectrum of the lateral velocity as shown in Figure 10, it can be found that the frequency of the tread lateral vibration is about $247 \mathrm{~Hz}$. The author's research team has carried out the sixcomponent test as shown in Figure 11 in which the follower wheel is equipped with the Wheel Force Transducer. It is found that the frequency of the lateral self-excited vibration is identified as $250 \mathrm{~Hz}$ [4]. This frequency is very close to $247 \mathrm{~Hz}$, which is the analysis result of the vibration model. This finding validates the tread vibration model from the frequency perspective.

As the vehicle velocity continues increasing to $149.5 \mathrm{~km} / \mathrm{h}$, the system tends to be stable again. Therefore, it can be concluded that when the vehicle velocity ranges from 81.7 to $149.5 \mathrm{~km} / \mathrm{h}$, the system vibration is periodic and the selfexcited vibration is generated on the tread. This speed range is

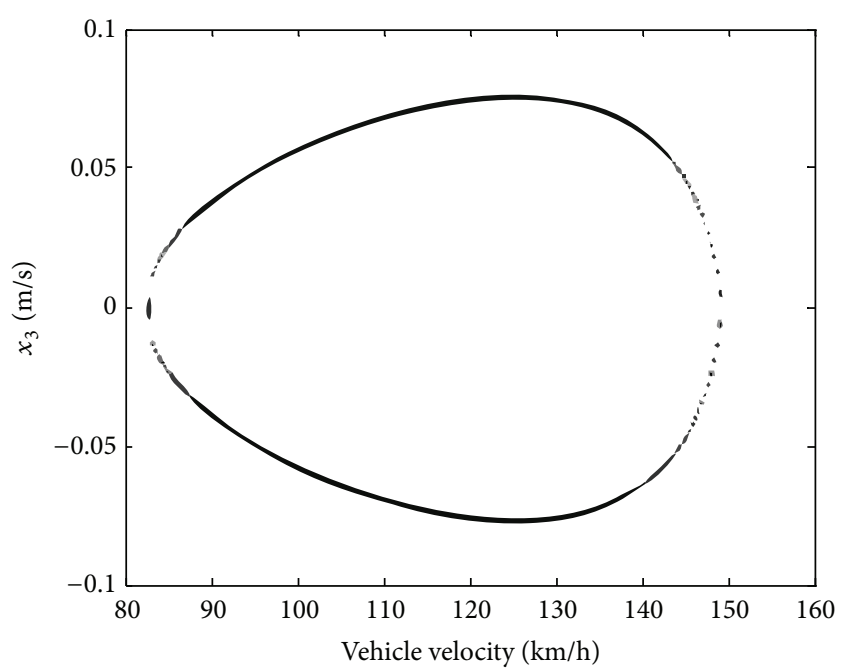

FIGURE 7: Bifurcation diagram of the lateral vibration with the variation of vehicle velocity.

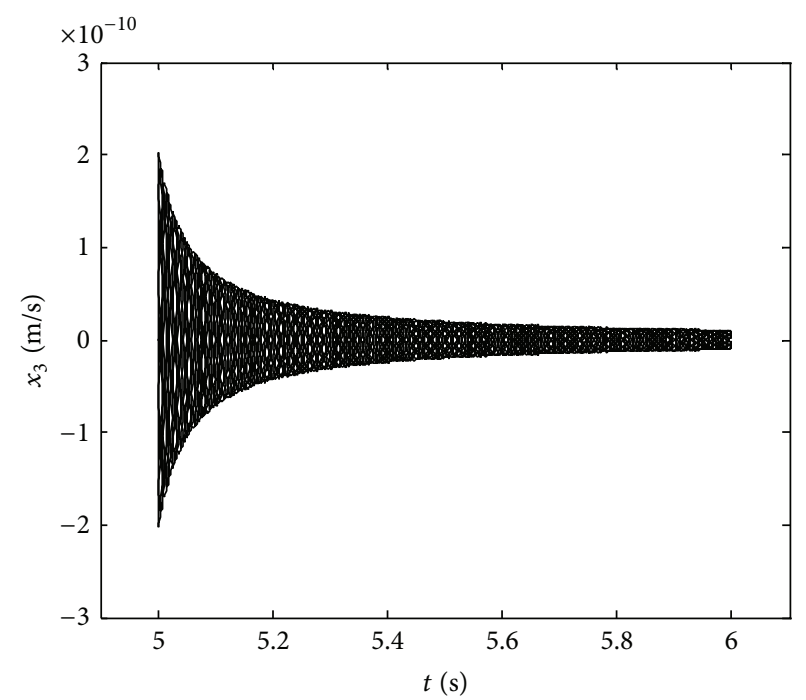

FIGURE 8: Phase diagram and time domain diagram at $78 \mathrm{~km} / \mathrm{h}$.

nearly the same as that shown in Figure 6. It turns out that tire polygonal wear may be caused when the vehicle is traveling in the specific speed range, which is consistent with the actual situation that the polygonal wear is caused when the vehicle travels at a high speed.

(2) Impact of the Toe-In Angle on the Lateral Vibration of the Follower Wheel. In the wheel alignment parameters, the toein angle is a vital factor affecting the tire polygonal wear. According to the previous research, the polygonal wear is more likely to happen when the vehicle is running on the highway. So the vehicle velocity is set to $120 \mathrm{~km} / \mathrm{h}$ and the other parameters are set as shown in Tables 1 and 2. Figure 12 is the bifurcation diagram with the variation of the toe-in angle.

As shown in Figure 12, tread self-excited vibration occurs when toe-in angle is between $0.204^{\circ}$ and $0.418^{\circ}$. Therefore, 


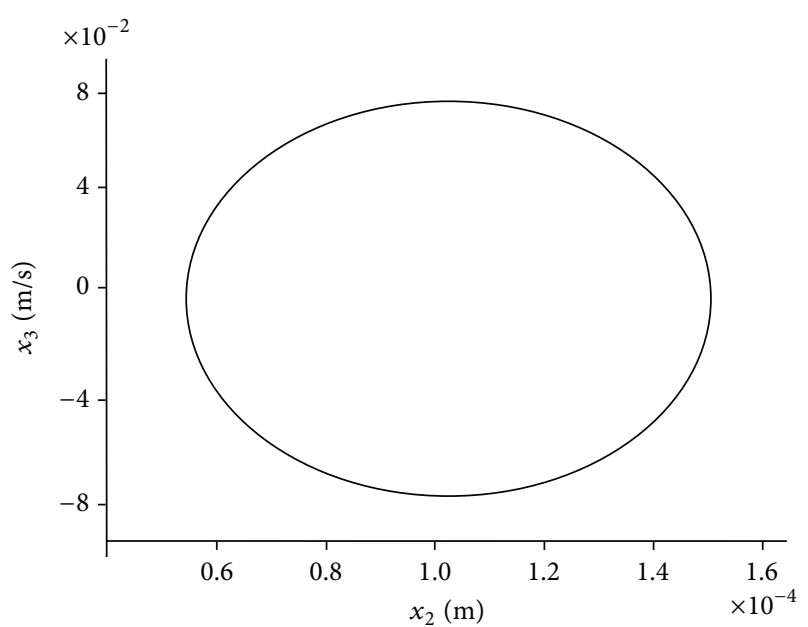

(a)

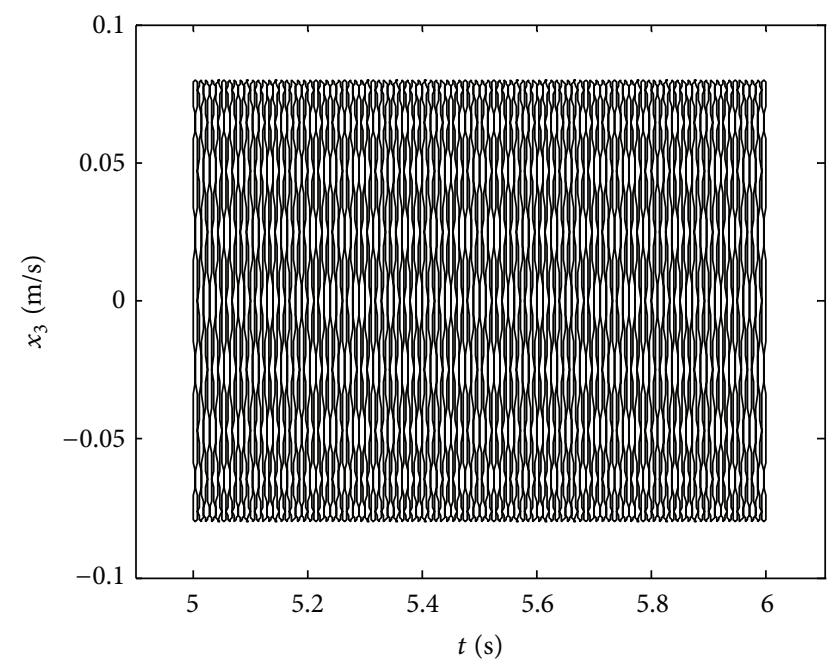

(b)

Figure 9: Phase diagram and time domain diagram at $108 \mathrm{~km} / \mathrm{h}$.

the occurrence of polygonal wear can be avoided or reduced by setting the wheel alignment parameters without involving the range between $0.204^{\circ}$ and $0.418^{\circ}$. It can be also found that the oscillating range of the system extends when the toe-in angle is increasing (Figure 13), which indicates that tread self-excited vibration becomes more violent when toein angle increases. In other words, the possibility of polygonal wear will be increased. This phenomenon corresponds to the characteristic that the polygonal wear is likely to occur with an unduly large toe-in angle.

(3) Impact of the Vertical Load on the Lateral Vibration of the Follower Wheel. From the equations above, it is known that the vertical load plays an important part in the tread lateral stiffness and its lateral force and it affects the tread lateral motion. For the research, the vertical load is set as a variable, the simulation vehicle velocity as $120 \mathrm{~km} / \mathrm{h}$, and other simulation parameters as shown in Tables 1 and 2 . Figure 14 is a bifurcation diagram showing that the tread

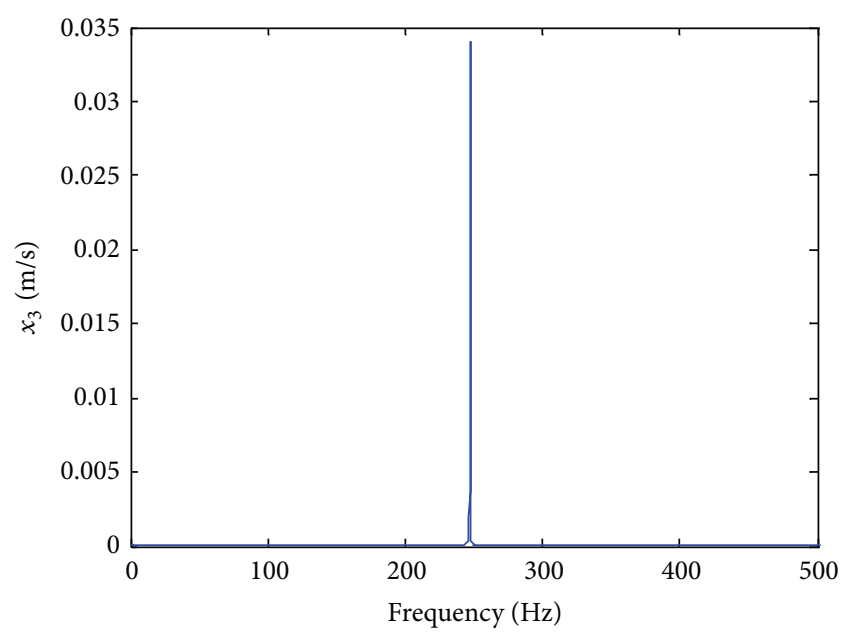

FIGURE 10: Self-power spectrum of the lateral velocity.

lateral vibration of the follower wheel is to occur with the variation of the vertical load.

As shown in Figure 14, the periodic oscillation of selfexcited vibration caused by Hopf bifurcation occurs when the vertical load is greater than $3510 \mathrm{~N}$. And the oscillation range expands with the increase of the vertical load which is shown in Figure 15. The tread lateral self-excited vibration becomes stronger, which indicates that the polygonal wear is likely to occur. It is concluded that the probability of polygonal wear will increase when the vehicle is overloaded.

(4) Impact of Tire Pressure on the Lateral Vibration of the Follower Wheel. Tire pressure affects the tire stiffness and wear greatly. The tire pressure is set as the bifurcate parameter to study how the tire pressure affects the dynamic behavior of the lateral vibration system of the follower wheel. The simulation vehicle velocity is set as $120 \mathrm{~km} / \mathrm{h}$, the tire pressure is set as a variable, and the other parameters are set as shown in Tables 1 and 2. Figure 16 is a bifurcation diagram showing that the tread lateral vibration of the follower wheel is to occur with the variation of the tire pressure.

As shown in Figure 16, the vibration system has stable periodic solutions when the tire pressure is low; that is, the lateral self-excited vibration is to occur. The amplitude of the periodic oscillation decreases with the increase of the tire pressure, as shown in Figure 17, indicating that tread lateral self-excited vibration is becoming weak and the possibility of the polygonal wear will be reduced. The lateral self-excited vibration disappears when the tire pressure is higher than $303 \mathrm{kPa}$. The result implies that the low pressure may cause the lateral self-excited vibration and the polygonal wear. This conclusion coincides with the occurrence characteristics of the polygonal wear.

4.2.2. Lateral Vibration Characteristics of Driving Wheel. In the following part, the lateral vibration characteristics of driving wheel will be analyzed. The identical method will be used to analyze the lateral vibration characteristics of driving wheel. This part will concentrate on how the vehicle velocity, 


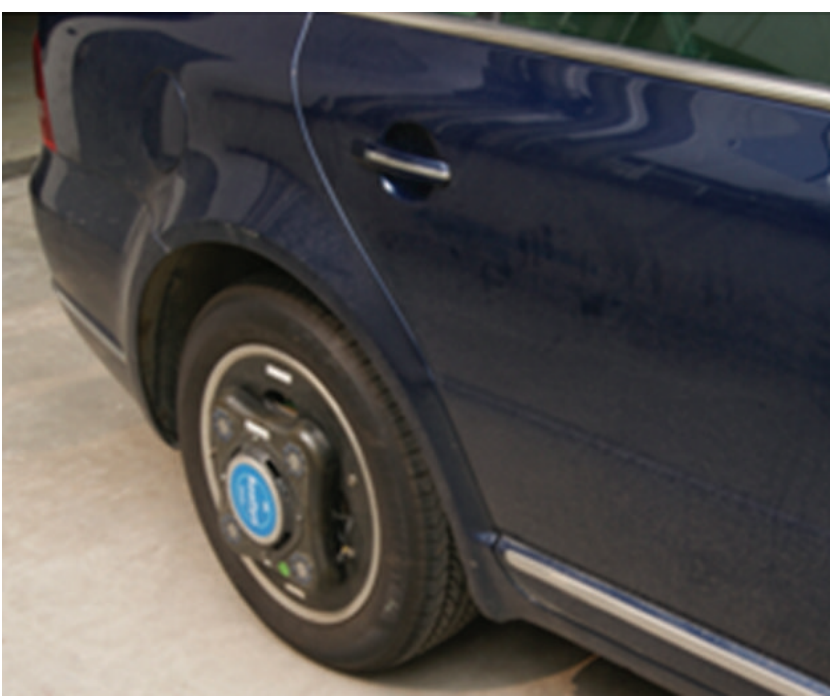

(a) Equipped wheel with the Wheel Force Transducer

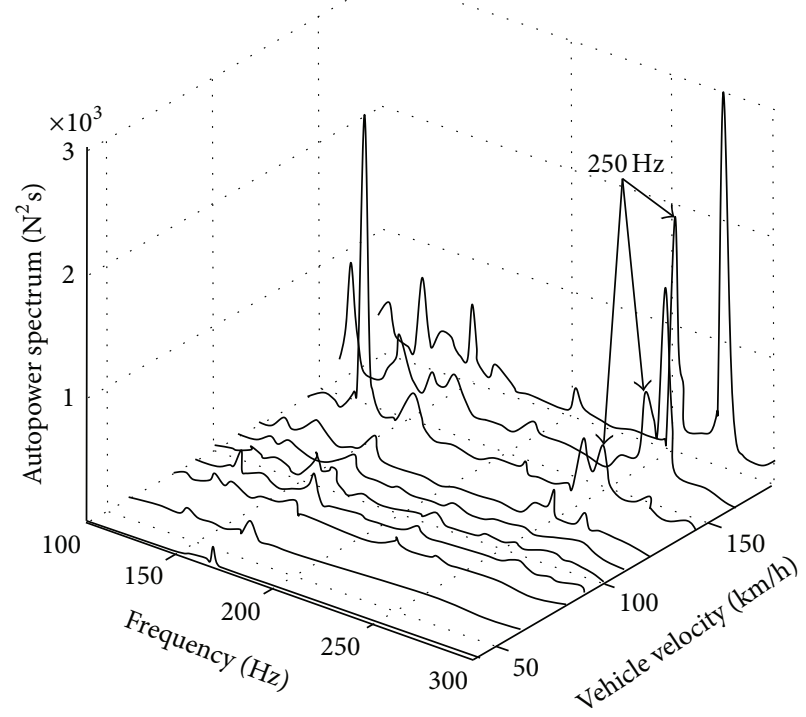

(b) Self-power spectrum of lateral force

Figure 11: Test verification of the tread vibration test.

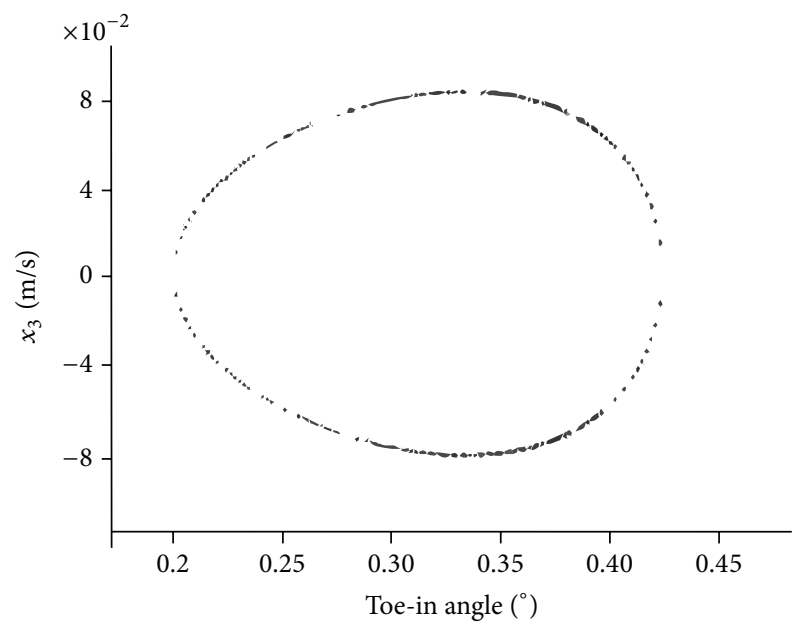

FIGURE 12: Bifurcation diagram with the variation of toe-in angle.

toe-in angle, vertical load, and tire pressure work on the lateral vibration characteristics of the driving wheel and then explain the phenomenon that the follower wheel is more likely to suffer polygonal wear than the driving one.

(1) Impact of the Vehicle Velocity on Lateral Vibration of the Driving Wheel. Figure 18 is the bifurcation diagram that the lateral vibration of the follower and driving wheels changes with the variation of vehicle velocity.

It can be found that the velocity range of driving wheel in which the lateral self-excited vibration occurs is smaller than that of the follower wheel in the same condition.

Figure 19 shows the oscillation range of the lateral vibration at $100 \mathrm{~km} / \mathrm{h}$. The lateral vibration of the driving wheel has a smaller oscillation range than that of the follower wheel

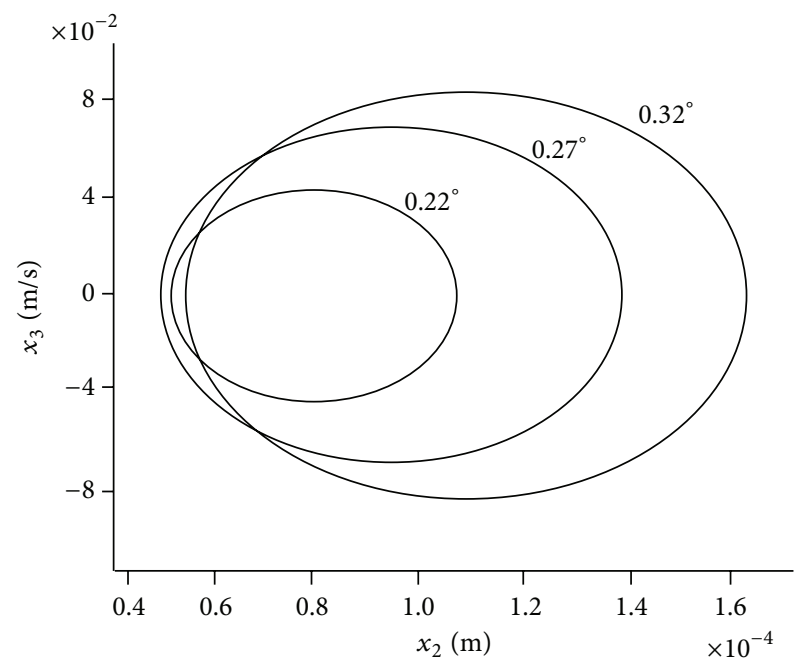

FIGURE 13: Phase diagram with the variation of toe-in angle.

at the same speed. The driving wheel vibrates less vigorously than the follower wheel does. Hence, the lateral self-excited vibration of the driving wheel is less likely to occur than that on the follower wheel.

(2) Impact of the Toe-In Angle on the Lateral Vibration of the Driving Wheel. The impact of the toe-in angle on the lateral vibration characteristics will be analyzed. For the convenience of the study, the simulation vehicle velocity is set as $120 \mathrm{~km} / \mathrm{h}$ and toe-in angle is a variable. Figure 20 is a bifurcation diagram showing the lateral vibration systems change with the variations of the toe-in angle.

It can be seen that the self-excited vibration occurs on the driving wheel when the toe-in angle is between $0.282^{\circ}$ and 


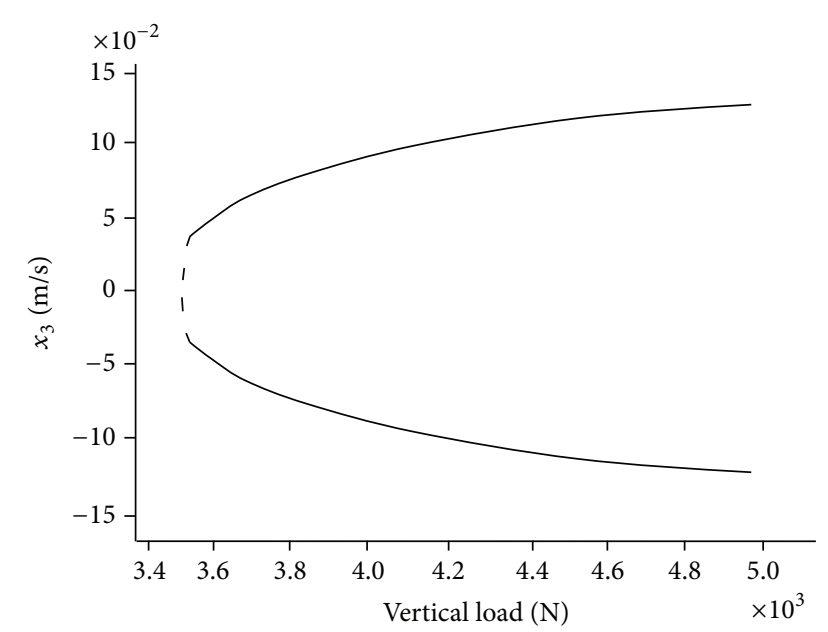

FIGURE 14: Bifurcation diagram with the variation of vertical load.

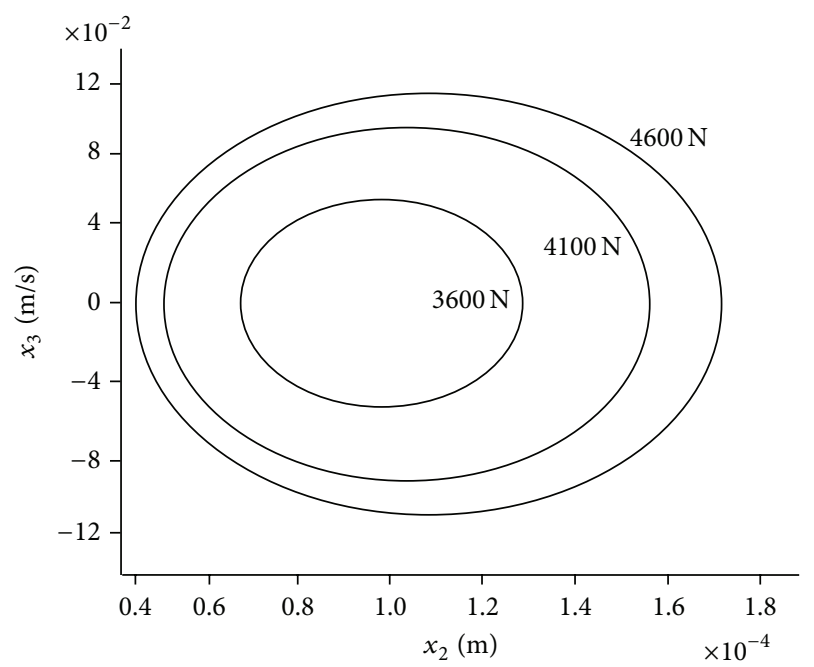

FIGURE 15: Phase diagram with the variation of vertical load.

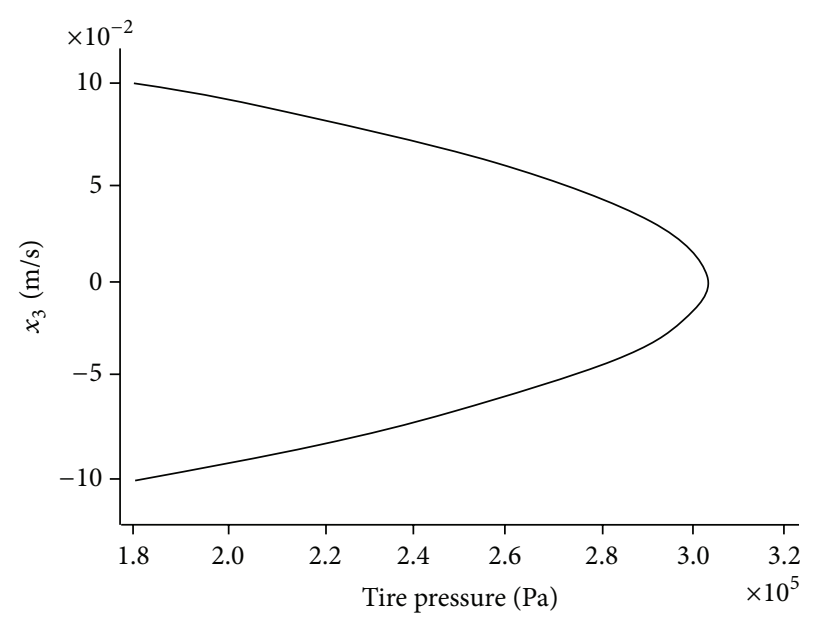

FIGURE 16: Bifurcation diagram with the variation of tire pressure.

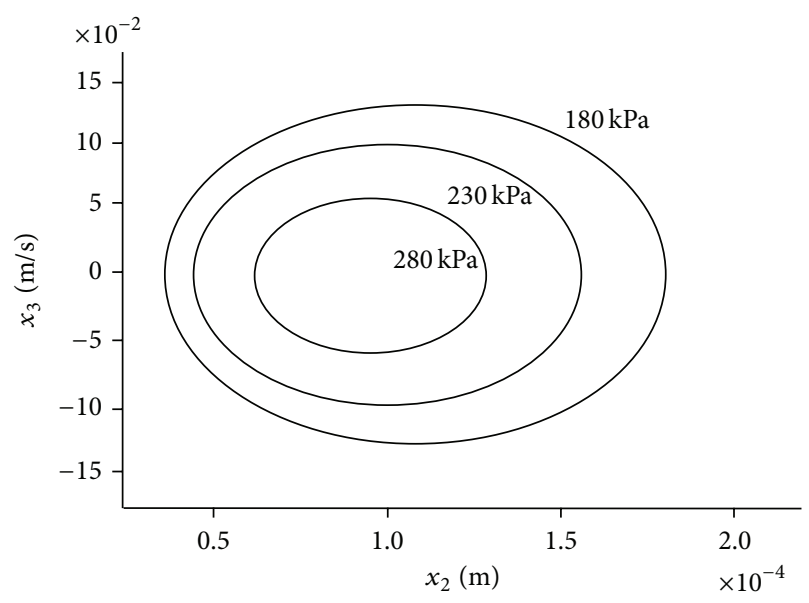

FIGURE 17: Phase diagram with the variation of tire pressure.

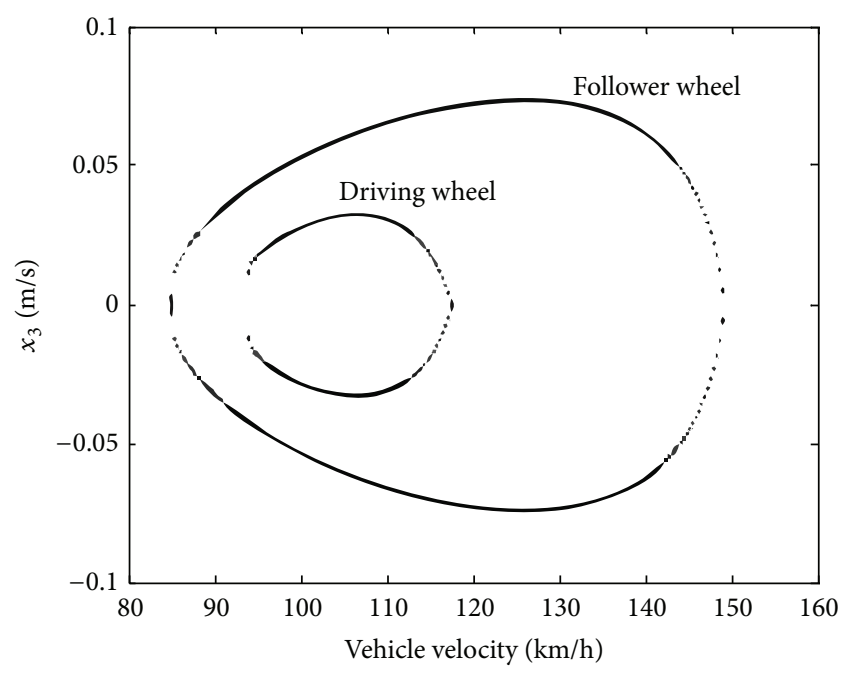

FIGURE 18: Bifurcation diagram of the lateral vibration with the variation of vehicle velocity.

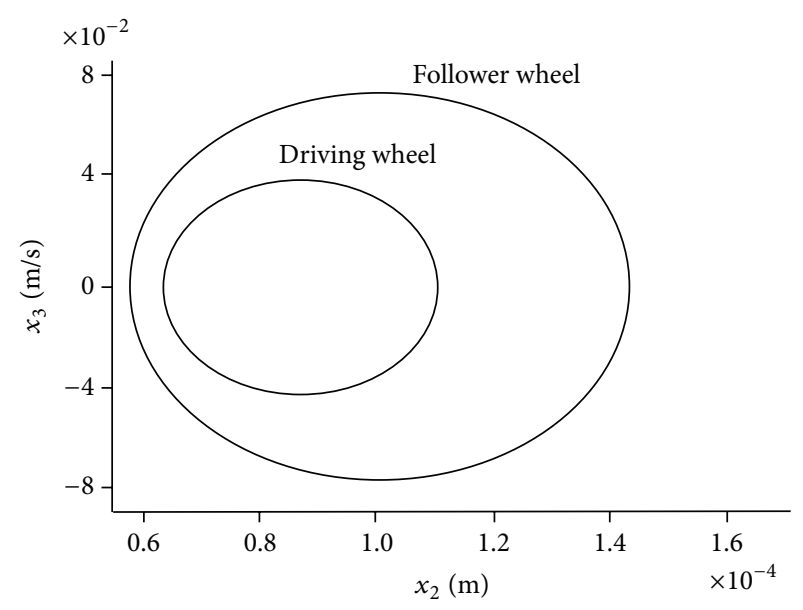

Figure 19: Phase diagram of the lateral vibration at $100 \mathrm{~km} / \mathrm{h}$. 


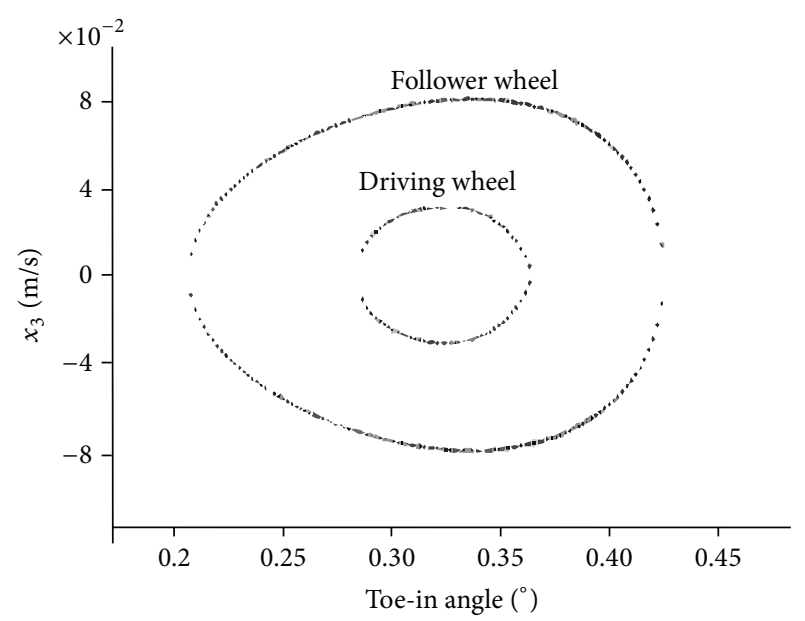

FIGURE 20: Phase diagram of the lateral vibration with the variation of toe-in angle.

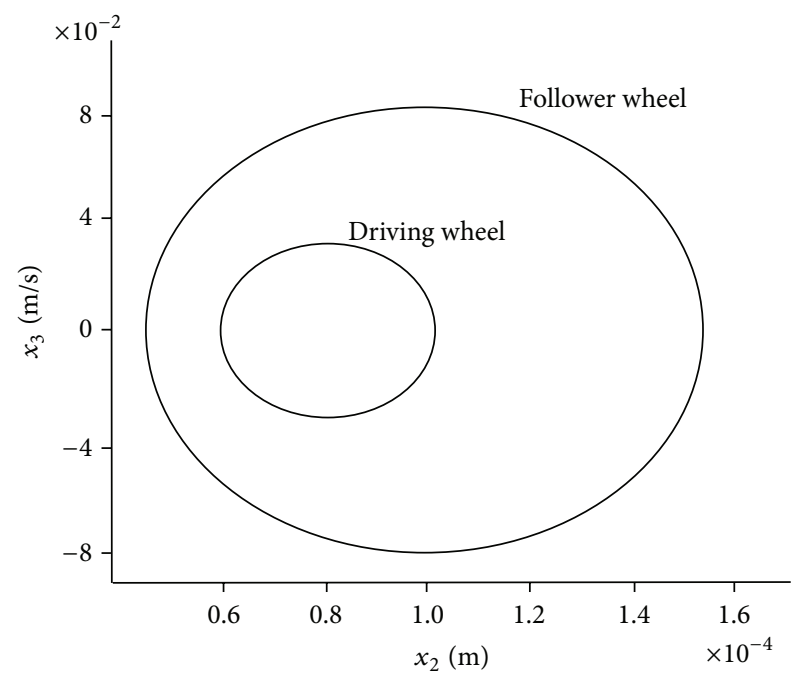

FIGURE 21: Phase diagram of the lateral vibration when the toe-in angle is $0.3^{\circ}$.

$0.358^{\circ}$. Compared with the follower wheel, the toe-in angle range under which the self-excited vibration happens on the driving wheel is obviously smaller. As shown in Figure 21, for the driving wheel, the oscillation range is also narrower and the vibration energy is lower when compared with the follower wheel. As a result, the polygonal wear is less likely caused on the driving wheel.

(3) Impact of the Vertical Load on the Lateral Vibration of the Driving Wheel. In this part, the simulation vehicle velocity is set as $120 \mathrm{~km} / \mathrm{h}$ and vertical load is a variable. Figure 22 is the bifurcation diagram showing the lateral vibration systems change with the variation of the vertical load.

It can be seen that the tread self-excited vibration occurs on the driving wheel when the vertical load is more than $4230 \mathrm{~N}$. Compared with the follower wheel, the vertical load range in which the self-excited vibration is caused on

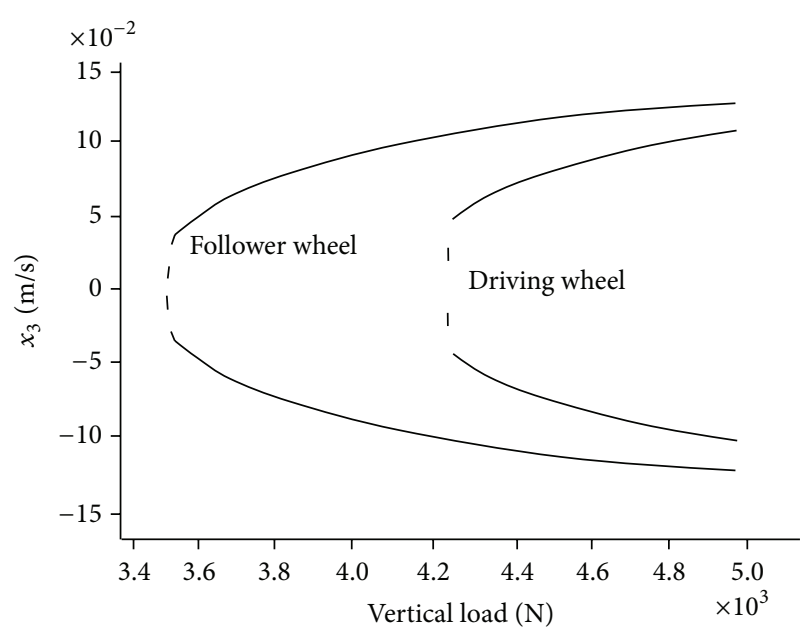

FIGURE 22: Bifurcation diagram of lateral vibration when the vertical load changes.

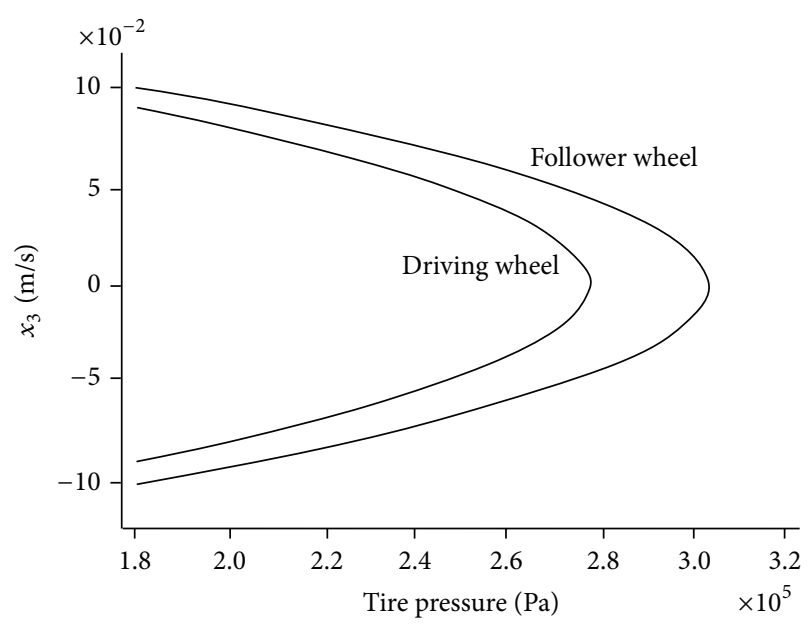

FIgURE 23: Bifurcation diagram of lateral vibration when the tire pressure changes.

the driving wheel is smaller. And the self-excited vibration energy of the driving wheel is lower than that on the follower wheel under the same load case. Under the normal load condition, the self-excited vibration will not be caused on the driving wheel.

(4) Impact of Tire Pressure on the Lateral Vibration of the Driving Wheel. In this part, the simulation vehicle velocity is set as $120 \mathrm{~km} / \mathrm{h}$ and the tire pressure is a variable. Figure 23 is the bifurcation diagram showing the lateral vibrations systems change with the varying tire pressure.

As indicated in Figure 23, the tire pressure range where lateral self-excited vibration occurs on the driving wheel is smaller than that on the follower wheel. The tread self-excited vibration occurs on the driving wheel only when the pressure is less than $272 \mathrm{kPa}$. And the vibration energy on the driving wheel is lower than that on the follower wheel at the same tire pressure. 
TABLE 3: The range of parameters.

\begin{tabular}{lcc}
\hline Parameters & The follower wheel & The driving wheel \\
\hline Vehicle velocity $(\mathrm{km} / \mathrm{h})$ & $81.7 \sim 149.5$ & $91.8 \sim 116.28$ \\
Toe-in angle $\left(^{\circ}\right)$ & $0.204 \sim 0.418$ & $0.282 \sim 0.358$ \\
Vertical load $(\mathrm{N})$ & $>3510$ & $>4230$ \\
Tire pressure $(\mathrm{kPa})$ & $<303$ & $<272$ \\
\hline
\end{tabular}

On the basis of the above analyses, the parameter ranges are shown in Table 3. The ranges in which the self-excited vibration is caused on the driving wheel are less than those on the follower wheel under the same working condition. Besides, the oscillation energy of the driving wheel is lower when compared with the follower wheel. Furthermore, under the normal pressure and load, the self-excited vibration cannot be caused on the driving wheel; that is, the polygonal wear is less likely to occur on the driving wheel. The research conducted has been used to explain the phenomenon that the follower wheel is more likely to suffer polygonal wear than the driving one.

This analysis result gives us the guidance to avoid the tread self-vibration. However, the research has not yet come to the conclusion concerning the direct relationship between the suspension parameters and the self-excited vibration. The optimization of the suspension will be carried out in the future after the analysis of the factors influencing the suspension system.

\section{Conclusion}

In this essay, a unified mechanical tire model is established to analyze the differences of the self-excited vibration characteristics between the driving and follower wheels. The results obtained are summarized as follows.

Firstly, the tire-road contact characteristics are analyzed, and the frictional force between the driving wheel with the slip angle and the road is obtained. Under a certain slip angle, the tread lateral force reduces gradually with the increase of the driving force. When the driving force is going up to a larger degree, the lateral force will decrease remarkably.

Secondly, the stability of the vibration system has been analyzed. Based on Lyapunov's stability theory, the conclusion is drawn that tire self-excited vibration is the periodic oscillation caused by the Hopf bifurcation. The analysis of the lateral vibration of the driving wheel shows that the system loses its stability and the self-excited vibration occurs when the wheel is traveling at a high speed, is over-loaded, is having a large toe-in angle, or is under a low tire pressure.

Finally, the differences of vibration characteristics between driving wheel and follower wheel are presented. The parameter ranges where the self-excited vibration occurs on the driving wheel are smaller than those on the follower wheel under the same working condition. Besides, the oscillation energy is lower when compared with the follower wheel. Furthermore, under the normal pressure and load, the self-excited vibration cannot be caused on the driving wheel; that is, the polygonal wear is less likely to occur on the driving wheel. The research conducted has been used to explain the phenomenon that the follower wheel is more likely to suffer polygonal wear than the driving one.

\section{Conflict of Interests}

The authors declare that there is no conflict of interests regarding the publication of this paper.

\section{Acknowledgments}

The authors gratefully acknowledge the fund supported by the National Nature Science Foundation of China (Grant no. 51375343) and the National Basic Research Program of China (Grant no. 2011CB711200).

\section{References}

[1] A. Sueoka, T. Ryu, T. Kondou, M. Togashi, and T. Fujimoto, "Polygonal wear of automobile tire," JSME International Journal. Series C: Dynamics, Control, Robotics, Design and Manufacturing, vol. 40, no. 2, pp. 209-217, 1997.

[2] K. Matsuzaki, A. Sueoka, T. Ryu, and H. Morita, "Generation mechanism of polygonal wear of work rolls in a hot leveler and a countermeasure by dynamic absorbers," International Journal of Machine Tools and Manufacture, vol. 48, no. 9, pp. 983-993, 2008.

[3] X. W. Yang, S. G. Zuo, and H. Huang, "Modeling and simulation analysis of rear axle with multi-degree-of-freedom," in Proceedings of the 3rd International Conference on Advanced Computer Theory and Engineering (ICACTE '10), vol. 5, pp. 1485-1488, Chengdu, China, August 2010.

[4] X. W. Yang, Modeling of self-excited vibration and study on key parameters in polygon wear of tire [Ph.D. thesis], Tongji University, Shanghai, China, 2011.

[5] Y. Li, S. Zuo, L. Lei, X. Yang, and X. Wu, "Characteristics' analysis of lateral vibration of tire tread," Journal of Vibration and Control, vol. 17, no. 14, pp. 2095-2102, 2011.

[6] J. D. Zhuang, Modern Automobile Tire Technology, Beijing Institute of Technology Press, Beijing, China, 2001, (Chinese).

[7] M. S. Yu, Friction and Wear and Lubrication Manua, China Machine Press, Beijing, China, 1985.

[8] W. J. Ding, Self-Excited Vibration, Tsinghua University Press, Beijing, China, 2009, (Chinese).

[9] C. Canudas de Wit, "A new model for control of systems with friction," IEEE Transactions on AUTomatic Control, vol. 43, no. 8, pp. 1189-1190, 1998.

[10] Q. S. Lu, Bifurcation and Singularity, Shanghai Science and Technology Education Press, Shanghai, China, 1995 (Chinese).

[11] E. L. B. van de Vorst, A. R. Kant, M. J. G. van de Molengraft, J. J. Kok, and D. H. van Campen, "Stabilization of periodic solutions of nonlinear mechanical systems: controllability and stability," Journal of Vibration and Control, vol. 4, no. 3, pp. 277-296, 1998.

[12] Z. S. Yu, Auto Theory, China Machine Press, Beijing, China, 2006, (Chinese).

[13] R. Dukkipati, J. Pang, M. S. Qatu et al., Road Vehicle Dynamics, SAE International, Warrendale, Pa, USA, 2008. 


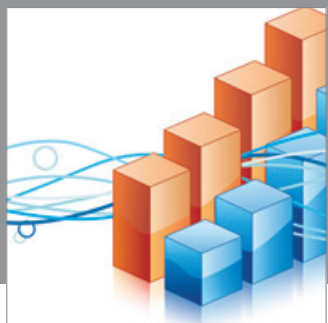

Advances in

Operations Research

mansans

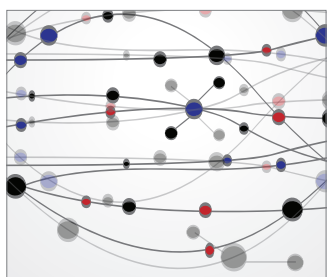

The Scientific World Journal
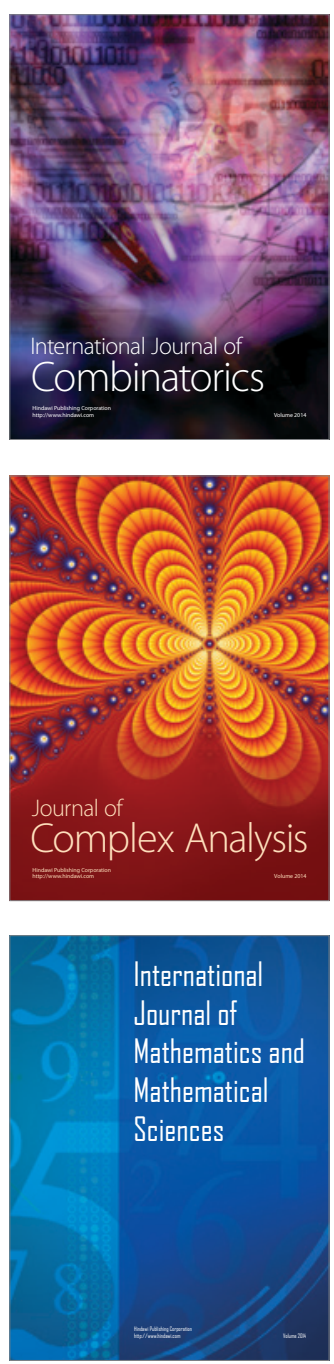
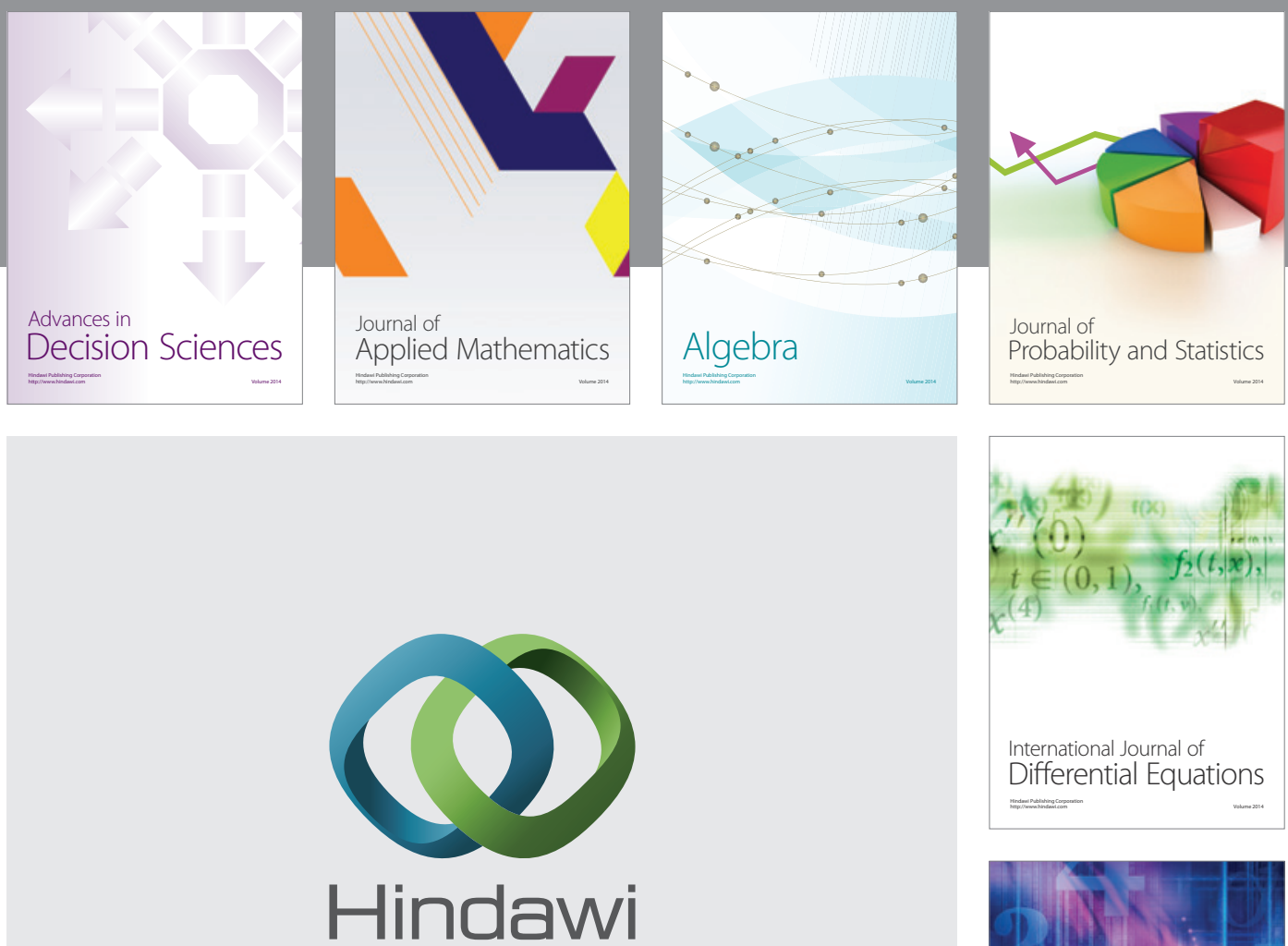

Submit your manuscripts at http://www.hindawi.com
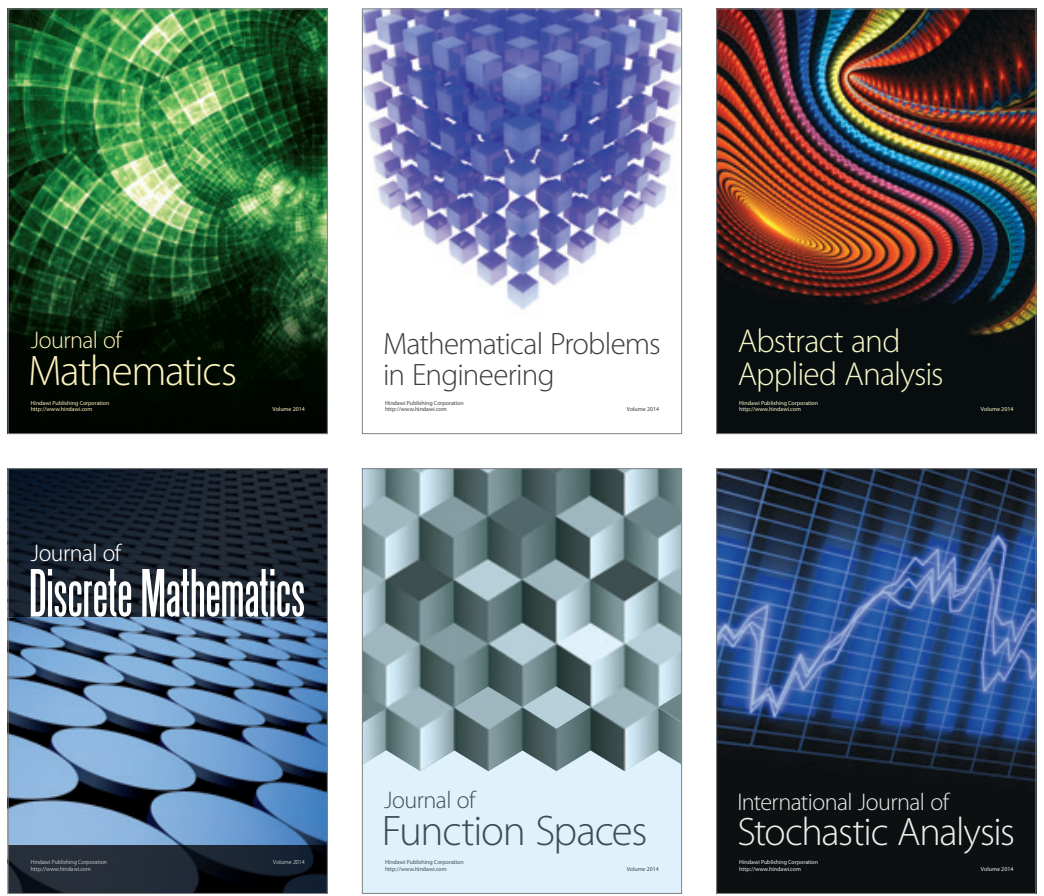

Journal of

Function Spaces

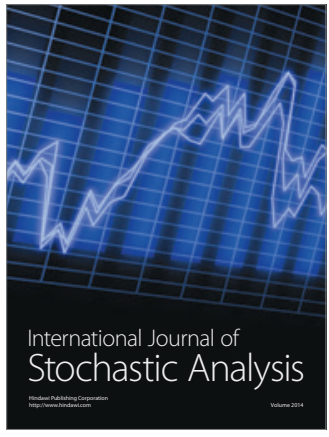

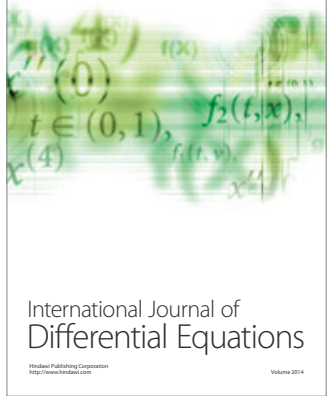
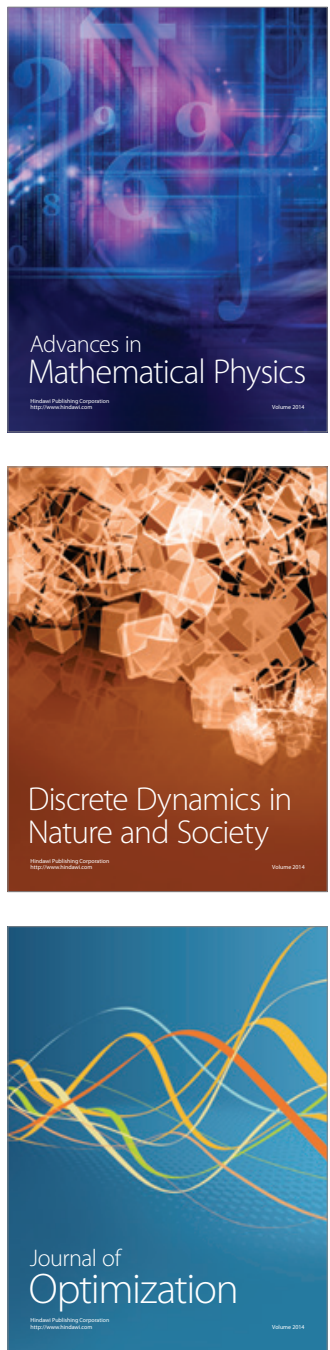